\title{
Optimization of technical measures for improving high-temperature performance of asphalt-rubber mixture
}

\author{
Chuan Xiao $\cdot$ Tianqing Ling $\cdot$ Yanjun Qiu
}

Received: 1 July 2013/Revised: 8 October 2013/Accepted: 9 October 2013/Published online: 26 October 2013

(C) The Author(s) 2013. This article is published with open access at Springerlink.com

\begin{abstract}
Asphalt-rubber pavements often become damaged in high-temperature regions and appear rutted or wavy, and experience slippage. To improve the high-temperature performance of the asphalt-rubber mixture, technical measurements, such as, the optimal adjustment of gradation, technique of composite modification, and control of compaction were investigated. An optimal adjustment of aggregate gradation based on stone matrix asphalt improves the high-temperature stability of the asphaltrubber mixture significantly. Through composite modification, the effect of asphalt-rubber modification was enhanced, and the dynamic stability and relative deformation indices of the asphalt-rubber mixture were improved significantly. Furthermore, compaction parameters had a significant influence on the high-temperature stability of the asphalt-rubber mixture. The rolling times for compacting the asphalt-rubber mixture should be controlled to within 18-20 round-trips at a molding temperature at $180{ }^{\circ} \mathrm{C}$; if the rolling time is a 12 round-trip, the compaction temperature of the asphalt-rubber mixture should be controlled between 180 and $190{ }^{\circ} \mathrm{C}$.
\end{abstract}

Keywords Road engineering · Optimization · Laboratory test $\cdot$ Asphalt-rubber mixture $\cdot$ High-temperature performance

C. Xiao $(\bowtie)$. Y. Qiu

School of Civil Engineering, Southwest Jiaotong University, P.O. Box 520, No. 111 First North Section, 2nd Ring Road,

Chengdu 610031, Sichuan, China

e-mail: xcaaa6666@sina.com

\section{T. Ling}

School of Civil Engineering and Architecture, Chongqing

Jiaotong University, Chongqing 400074, China

\section{Introduction}

Rapid growth of waste tires is a serious environmental problem because of their highly resistant chemical, biological, and physical properties. Many approaches have been considered to encourage the sustainable development. Using crumb rubber in asphalt, which initiated with the motivation to improve the binder properties, is one of the practical ways to tackle the increasing waste tires.

In general, the approaches used to incorporate crumb rubber modifier $(\mathrm{CRM})$ in road paving materials are classified as the dry method and the wet method [2]. Wet method is applied in most of the rubberized asphalt projects in China, which entails adding the crumb rubber to the binder before mixing it with aggregate [3]. The behavior of asphalt-rubber with wet method depends on several factors, such as, the origin, fabrication process and grain size distribution of the crumb rubber, the type of base asphalt binder used in the mixture, and the temperature and time of the mixing process. Anderson et al. [4] investigated the rheological and physical properties of binders modified with rubber, for rubber contents below $20 \%$ by weight. Huang et al. [5] and Shen and Amirkhanian [6] suggested the optimal preparation of asphalt-rubber according to comparative tests on material properties of asphalt binder.

In pavement destruction, asphalt-rubber has become increasingly attractive in the applications, such as, open graded friction course (OGFC), stress absorption membrane interlayer (SAMI), and super silent pavement (SSP) [2]. The asphalt-rubber pavements exhibit unique advantages in reducing pavement thickness, delaying reflection cracking, and decreasing traffic noise [7, 8]. However, an obvious problem in the application of the asphalt-rubber mixture is the lack of high-temperature stability used as structural layer, which could cause serious rutting under recycled 
vehicle loading. The indices, such as, viscosity, penetration, and softening point show that the asphalt-rubber shows excellent performance at high-temperature [9]. However, because of the interference of asphalt-rubber and aggregate during the compacting process and the low stiffness modulus and deformation characteristics of the asphalt-rubber mixture $[8,10]$, it is difficult to meet the desired demands when applying asphalt-rubber pavement in high-temperature regions. Furthermore, there is no unified technical specification for asphalt-rubber in China resulting in significant discrepancies in aggregate gradation, asphalt content, and mineral filler content when paving with asphalt-rubber mixture [11-13]. Improvements in the hightemperature performance of asphalt-rubber pavements are critical when they are applied in high-temperature regions and under heavy traffic conditions in China.

In this paper, we investigate the high-temperature stability of an asphalt-rubber mixture based on internal and external factors. At first, the optimal gradation was adjusted in the rutting tests with dynamic stability and relative deformation as evaluation indices. Then, the scheme of compound modification and optimization of the compaction parameters were analyzed to improve the high-temperature stability of the asphalt-rubber mixture. To obtain a reasonable scheme of compound modification, comparative tests of high-temperature performance were conducted between different binders and mixtures. The effects of rolling time and molding temperature on air void volume and the dynamic stability (DS) were investigated to determine optimal compaction parameters.

\section{Test materials}

\subsection{Material properties of asphalt-rubber}

SK 70\# base asphalt and crumb rubber (30 mesh size) were used to produce asphalt-rubber for comparative tests of asphalt-rubber performance. The test methods followed "Standard Test Methods of Bitumen and Bituminous Mixtures for Highway Engineering" from the industry standard of China (JTG E20-2011) [14] with main performance indices listed in Table 1.
2.2 Material properties of aggregate and filler

The test methods followed "Test Methods of Aggregate for Highway Engineering" (JTG E42-2005) and the main indices of the aggregate and mineral filler in the asphaltrubber mixtures are listed in Tables 2 and 3, respectively.

\section{Test method and analysis}

\subsection{Optimization of aggregate gradation}

\subsubsection{Gradation-type selection}

Based on the broad overview of a typical gradation type for an asphalt-rubber mixture, AR-AC-13 (based on Arizona standards [2, 12]), SMA-13 (traditional stone matrix asphalt [15]), and AC-13 (dense-graded asphalt mixture [15]) were chosen as research materials on which to conduct the rutting tests. Figure 1 shows the aggregate gradations of different mixtures.

The rutting tests on the different asphalt mixtures followed "Standard Test Methods of Bitumen and Bituminous Mixtures for Highway Engineering" (JTG E20-2011) with parameters listed in Table 4.

The rutting test results for the different asphalt mixtures are given in Table 5.

Table 5 shows that the preferential order of the three kinds of mixtures based on high-temperature performance is: SMA-13 $>$ AR-AC-13 $>$ AC-13. This occurs because of the different characteristics of the mixtures.

Because AC-13 is a "suspend-dense" structure mixture, there is interference between the asphalt-rubber binder and the aggregate during compaction. This type of mixture is difficult to compact completely with asphalt-rubber. This most likely explains why the high-temperature performance indices of AC-13 are the worst among the three kinds of asphalt mixtures.

AR-AC-13 has an aggregate gradation based on the Arizona standard with obvious gap gradation characteristics. By enhancing the high viscosity binder dosage and reducing the amount of fine aggregate, especially the filler, more voids appear in the mineral aggregate of AR-AC-13 and more

Table 1 Properties of asphalt-rubber

\begin{tabular}{lcll}
\hline Performance index & Value & Technical standard [9] & Test method \\
\hline $180{ }^{\circ} \mathrm{C}$ rotation viscosity (Pa s) & 2.8 & $2.5-5.0$ & T 0625 \\
Softening point $\left({ }^{\circ} \mathrm{C}\right)$ & 67.6 & $>65$ & T 0606 \\
Penetration $(0.1 \mathrm{~mm})$ & 50.4 & $30-70$ & $\mathrm{~T} 0604$ \\
Elastic recovery $(\%)$ & 78.0 & $\geq 60$ & T 0662
\end{tabular}

Note The code of test method followed JTG E20-2011 [14] 
Table 2 Properties of aggregate

\begin{tabular}{|c|c|c|c|c|c|c|c|c|}
\hline $\begin{array}{l}\text { Aggregate } \\
\text { type }\end{array}$ & $\begin{array}{l}\text { Apparent } \\
\text { density } \\
\left(\mathrm{g} \cdot \mathrm{cm}^{-3}\right)\end{array}$ & $\begin{array}{l}\text { Bulk } \\
\text { density } \\
\left(\mathrm{g} \cdot \mathrm{cm}^{-3}\right)\end{array}$ & $\begin{array}{l}\text { Crushed } \\
\text { stone value } \\
(\%)\end{array}$ & $\begin{array}{l}\text { Water-washing } \\
\text { method } \\
<0.075 \mathrm{~mm}(\%)\end{array}$ & $\begin{array}{l}\text { Flat and elongated } \\
\text { particle in coarse } \\
\text { aggregate }(\%)\end{array}$ & $\begin{array}{l}\text { Water } \\
\text { absorption } \\
(\%)\end{array}$ & $\begin{array}{l}\text { Sturdiness } \\
(\%)\end{array}$ & $\begin{array}{l}\text { Sand } \\
\text { equivalent } \\
(\%)\end{array}$ \\
\hline $\begin{array}{c}10-15 \mathrm{~mm} \\
\text { gravel }\end{array}$ & 2.928 & 2.834 & 11.2 & 0.2 & 7.8 & 1.84 & 0.3 & - \\
\hline $\begin{array}{c}5-10 \mathrm{~mm} \\
\text { gravel }\end{array}$ & 2.912 & 2.826 & 11.6 & 0.2 & 7.1 & 1.88 & 0.3 & - \\
\hline Stone chip & 2.725 & 2.725 & - & - & - & - & 1.2 & 78.4 \\
\hline
\end{tabular}

Table 3 Properties of filler

\begin{tabular}{lllllllll}
\hline $\begin{array}{l}\text { Apparent density } \\
\left(\mathrm{g} \cdot \mathrm{cm}^{-3}\right)\end{array}$ & $\begin{array}{l}\text { Hydrophilic } \\
\text { coefficient }\end{array}$ & $\begin{array}{l}\text { Plasticity } \\
\text { index }(\%)\end{array}$ & $\begin{array}{l}\text { Water } \\
\text { content }(\%)\end{array}$ & Heating stability & Pass percentage $(\%)$ & \\
\hline 2.710 & 0.6 & 2.2 & 0.43 & $\begin{array}{c}\text { Color did not change } \\
\text { at } 200{ }^{\circ} \mathrm{C}\end{array}$ & $\begin{array}{l}<0.6 \mathrm{~mm} \\
100.0\end{array}$ & $\begin{array}{c}<0.3 \mathrm{~mm} \\
99.9\end{array}$ & $<0.15 \mathrm{~mm}$ & $<0.075 \mathrm{~mm}$ \\
& & & & 97.2 & 91.8 & \\
\hline
\end{tabular}

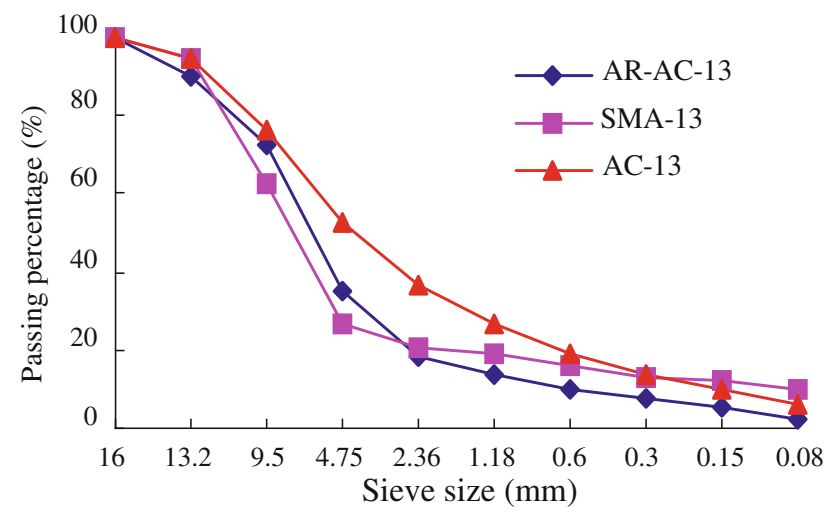

Fig. 1 Comparison of aggregate gradation

Table 4 Rutting test parameters

\begin{tabular}{ll}
\hline Test parameters & Value \\
\hline Molding method & Wheel molding \\
Specimen size & $300 \times 300 \times 50 \mathrm{~mm}$ \\
Test temperature & $60 \pm 1{ }^{\circ} \mathrm{C}$ \\
Pressure & $0.7 \pm 0.05 \mathrm{MPa}$ \\
Loading distance & $230 \pm 10 \mathrm{~mm}$ \\
Loading speed & $42 \pm 1 \mathrm{times} \mathrm{min}^{-1}$ \\
\hline
\end{tabular}

significant features appear in the framework structure. However, rutting test results show that the typical "S" gradation type did not reach the expected target. One factor that contributes to the problem may be that with a reduction in filler, the asphalt mortar stiffness is reduced making the mixture prone to deformation. It is therefore difficult to achieve cohesion and stability in the AR-AC-13 mixture.

SMA-13 is also a gap gradation mixture, but compared with AR-AC-13, the asphalt-rubber mixture based on traditional SMA-13 has more fine aggregate and less asphalt binder proportion, and the deficiencies in AR-AC-13 can be overcome.

\subsubsection{Gradation optimization}

The rutting test results of SMA-13 with the asphalt-rubber were unable to meet heavy traffic demands [11]. We therefore selected SMA-13 (AR-SMA-13) for further adjustment of aggregate gradation. The optimal adjustment of the passing percentages through crucial sieves was studied to improve the high-temperature performance of AR-SMA-13. The key sieves for aggregate gradation were selected because: (1) the aggregate gradation should form a framework structure with excellent strength; (2) crumb rubber is coarse compared with conventional modifiers and

Table 5 Rutting test results for different asphalt mixtures

\begin{tabular}{llll}
\hline Mixture type & Asphalt content $(\%)$ & Dynamic stability (times $\left.\mathrm{mm}^{-1}\right)$ & Relative deformation $(\%)$ \\
\hline AR-AC-13 & 7.0 & 1,721 & 4.3 \\
SMA-13 & 5.8 & 3,219 & 2.9 \\
AC-13 & 4.3 & 1,480 & 5.2 \\
\hline
\end{tabular}

Note Dynamic stability is defined as the axle loading time when the mixture specimen generates a 1-mm deformation. Relative deformation is defined as the ratio between final deformation and original mixture specimen height [11] 
it is necessary to decrease the filler proportion of ARSMA-13 and increase voids in the mineral aggregate (VMA) so that there is enough filling space for the asphaltrubber binder in the asphalt-rubber mixture; and (3) $2.36 \mathrm{~mm}$ is an important sieve size for aggregate gradation. The variation in the $2.36-\mathrm{mm}$ passing percentage would not influence the mixture volume parameters significantly. It is therefore helpful to reduce the influence caused by variability in the other volume parameters.

As discussed above, the passing percentages through the 0.075- and 2.36-mm sieve sizes were selected as crucial sieves upon which to make adjustments. The changes in pass percentage are shown in Table 6 .

Hot mix asphalt was designed according to the Marshall test [15] with results given in Table 7 (where VV is the volume of air voids and VFA is voids filled with asphalt).

Rutting tests [14] were conducted to determine the optimal gradation type for AR-SMA-13. The DS and relative deformation were chosen as evaluation indices. Table 8 shows the differences among the three types of mixtures from the rutting tests.

As shown in Table 8, the high-temperature stability of AR-SMA-13I reduced the filler proportion from $10 \%$ to $8 \%$, yielded a better mixture than the other two types, and is the only mixture that meets the technical standards. Gradation adjustment to optimize the high-temperature performance of AR-SMA-13 is therefore feasible.

\subsection{Compound modification}

\subsubsection{Preparation of compound-modified sample}

Styrene-butadiene block copolymer (SBS) and viscosityreducing additive (termed SAK) were chosen as modifiers to study compound modification on asphalt-rubber. Based on the different properties of SBS [16, 17] and SAK [18], different preparation programs were formulated for the two types of compound-modified asphalt-rubber:

(1) SBS-Rubber compound-modified asphalt (termed S-R asphalt): (a) heat base asphalt to $180{ }^{\circ} \mathrm{C}$, add SBS $(2 \%)$ into base asphalt, and shear for $30 \mathrm{~min}$ using an emulsion shear apparatus at $180{ }^{\circ} \mathrm{C}$ and $3,500 \mathrm{rpm}$; (b) swell and develop for $30 \mathrm{~min}$ at $150{ }^{\circ} \mathrm{C}$ by manual mixing; (c) heat modified asphalt to $190-200{ }^{\circ} \mathrm{C}$, add dry crumb rubber and then shear and develop for 45-60 min using an emulsion shear apparatus at $3,000 \mathrm{rpm}$.

(2) SAK-Rubber compound-modified asphalt (termed $\mathrm{K}-\mathrm{R}$ asphalt): (a) heat base asphalt to $150{ }^{\circ} \mathrm{C}$, add SAK $(2.5 \%)$ into base asphalt, and mix by hand; (b) heat modified asphalt to $190-200{ }^{\circ} \mathrm{C}$, add dry crumb rubber, then shear and develop for 45-60 min at $3,000 \mathrm{rpm}$.

\subsubsection{Asphalt binder tests}

Pure asphalt-rubber, SBS asphalt, S-R asphalt, and K-R asphalt were selected to analyze the asphalt binder properties. The evaluation indices chosen were $180{ }^{\circ} \mathrm{C}$ rotation viscosity, penetration, softening point, and elastic recovery with results shown in Fig. 2.

Comparative test results for the different asphalt-rubber types show that the high-temperature performance of all three types of asphalt-rubber (pure, S-R, and K-R) was better than SBS asphalt. In terms of compound modification: (1) S-R asphalt exhibits a better high-temperature performance for all indices compared with pure asphaltrubber; the $180{ }^{\circ} \mathrm{C}$ rotation viscosity, softening point, and elastic recovery increased by $10.7,17.6$, and $3.8 \%$,

Table 6 Adjustment of aggregate gradation

\begin{tabular}{llllllllll}
\hline Gradation type & \multicolumn{2}{l}{ Pass percentage $(\%)$} & & & \\
\cline { 2 - 9 } & $13.2 \mathrm{~mm}$ & $9.5 \mathrm{~mm}$ & $4.75 \mathrm{~mm}$ & $2.36 \mathrm{~mm}$ & $1.18 \mathrm{~mm}$ & $0.6 \mathrm{~mm}$ & $0.3 \mathrm{~mm}$ & $0.15 \mathrm{~mm}$ & $0.075 \mathrm{~mm}$ \\
\hline Standard gradation [15] & 95 & 62.5 & 27 & 20.5 & 19 & 16 & 13 & 12 & 10 \\
Gradation I & 95 & 62.5 & 27 & 18.5 & 17 & 14 & 11 & 10 & 8 \\
Gradation II & 95 & 62.5 & 27 & 16.5 & 15 & 12 & 9 & 8 & 6 \\
\hline
\end{tabular}

Table 7 Results from the Marshall test

\begin{tabular}{llllllll}
\hline Gradation type & $\begin{array}{l}\text { Asphalt content } \\
(\%)\end{array}$ & $\begin{array}{l}\text { Bulk density } \\
\left(\mathrm{g} \cdot \mathrm{cm}^{-3}\right)\end{array}$ & VV (\%) & $\begin{array}{l}\text { VMA } \\
(\%)\end{array}$ & VFA (\%) & $\begin{array}{l}\text { Marshall stability } \\
(\mathrm{kN})\end{array}$ & $\begin{array}{l}\text { Flow value } \\
(\mathrm{mm})\end{array}$ \\
\hline Standard gradation & 5.8 & 2.435 & 4.2 & 17.1 & 75.4 & 7.94 & 2.63 \\
Gradation I & 6.0 & 2.444 & 4.3 & 17.5 & 75.4 & 8.02 & 2.31 \\
Gradation II & 6.1 & 2.437 & 4.1 & 17.6 & 76.7 & 8.21 & 2.57 \\
\hline
\end{tabular}


Table 8 Comparison of different mixtures for high-temperature performance

\begin{tabular}{llllll}
\hline Mixture type & \multicolumn{2}{l}{$\begin{array}{l}\text { Dynamic stability } \\
\left(\text { times } \mathrm{mm}^{-1} \text { ) }\right.\end{array}$} & & \multicolumn{2}{l}{$\begin{array}{l}\text { Relative deformation } \\
(\%)\end{array}$} \\
\cline { 2 - 3 } \cline { 5 - 6 } \cline { 5 - 6 } & Test value & Standard & & Test value & Standard \\
\hline AR-SMA-13 & 3,219 & $\geq 3,500$ & & 4.3 & $\leq 3.1$ \\
AR-SMA-13I & 3,688 & & 2.9 & \\
AR-SMA-13II & 3,275 & & 5.2 & \\
\hline
\end{tabular}

respectively, while the $25{ }^{\circ} \mathrm{C}$ penetration decreased by $4.6 \%$. (2) SAK addition (viscosity-reducing additive) resulted in a K-R $180{ }^{\circ} \mathrm{C}$ rotation viscosity reduction of $60.7 \%$ compared with pure asphalt. This helps enhance mixture compactness and provide structural strength. The $25{ }^{\circ} \mathrm{C}$ penetration of the K-R asphalt decreased by $7.1 \%$. Its softening point and elastic recovery increased by 28.3 and $1.3 \%$, respectively.

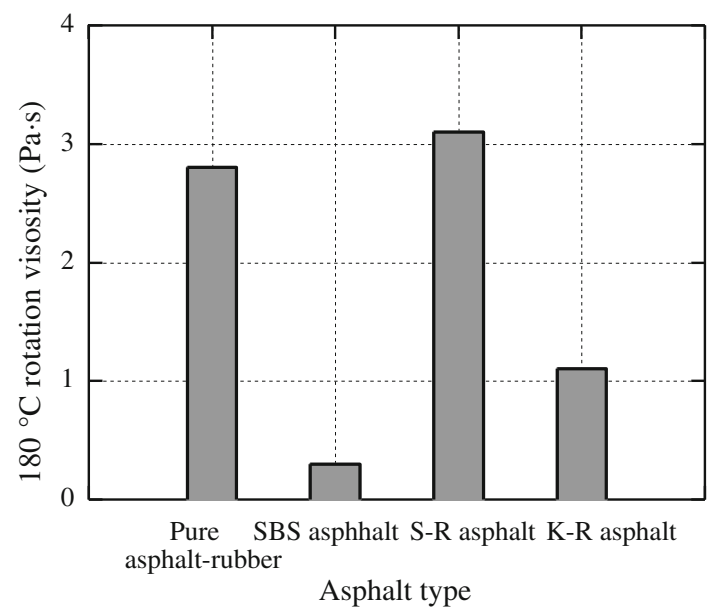

(a) $180^{\circ} \mathrm{C}$ rotation viscosity

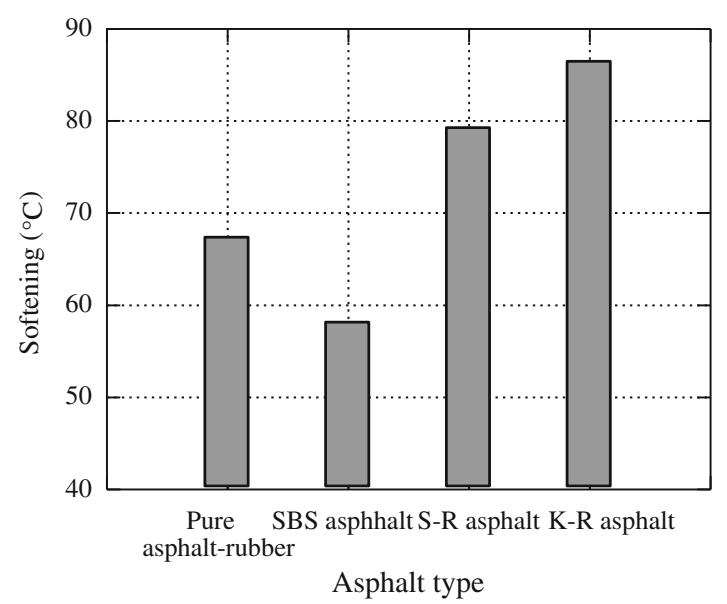

(c) Softening point
Compound modification in asphalt binder tests is therefore significant with the comprehensive high-temperature performance of the S-R asphalt being better than the other asphalt types.

\subsubsection{Asphalt mixture tests}

Rutting tests were conducted on the SBS asphalt mixture without fiber (SBS-SMA-13), asphalt-rubber mixture (ARSMA-13), SBS-AR compound-modified mixture (SBSAR-SMA-13), and SAK-AR compound-modified mixture (SAK-AR-SMA-13) with results shown in Fig. 3.

The following is concluded from the graphical illustrations in Fig. 3:

(1) Based on the DS and relative deformation, the preferential order of the four kinds of mixtures was: SBS-ARSMA-13 $>$ SAK-AR-SMA-13 $\approx$ SBS-SMA-13 $>$ ARSMA-13.

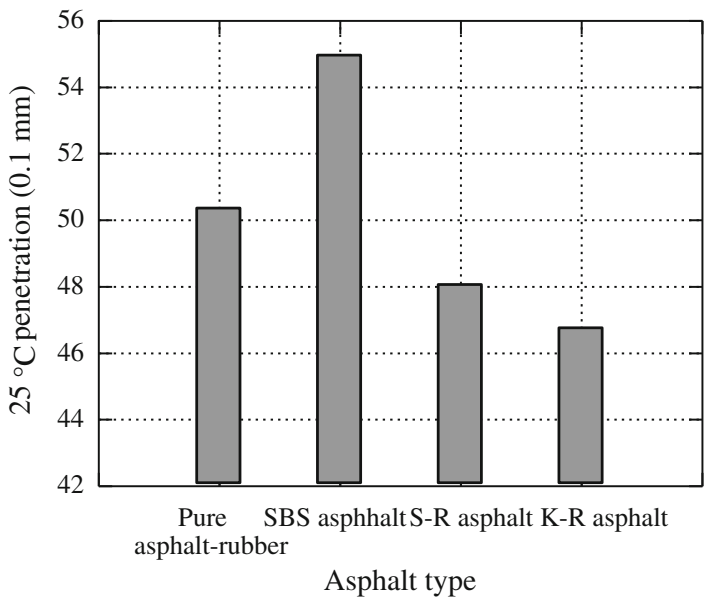

(b) $25^{\circ} \mathrm{C}$ penetration

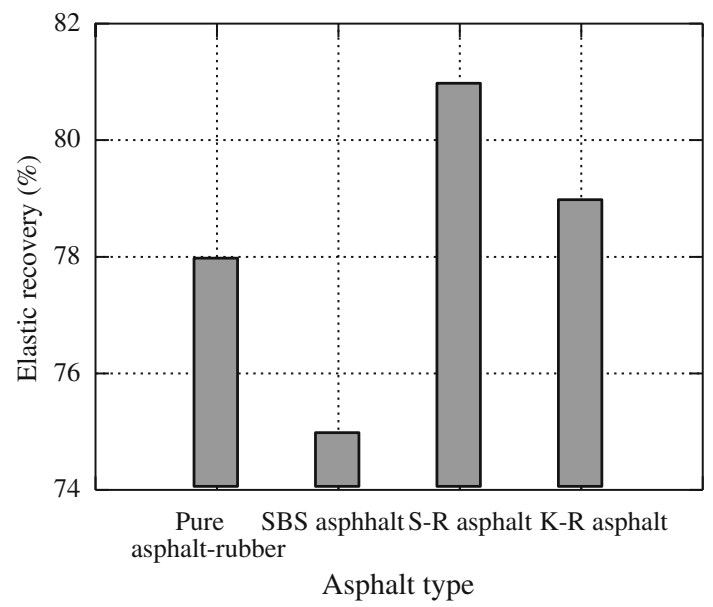

(d)Elastic recovery

Fig. 2 Comparison of asphalt binder test results 


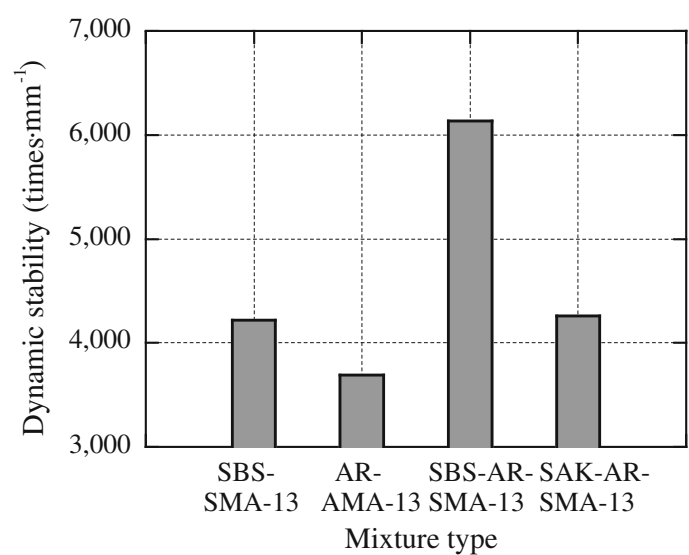

(a) Dynamic stabilities

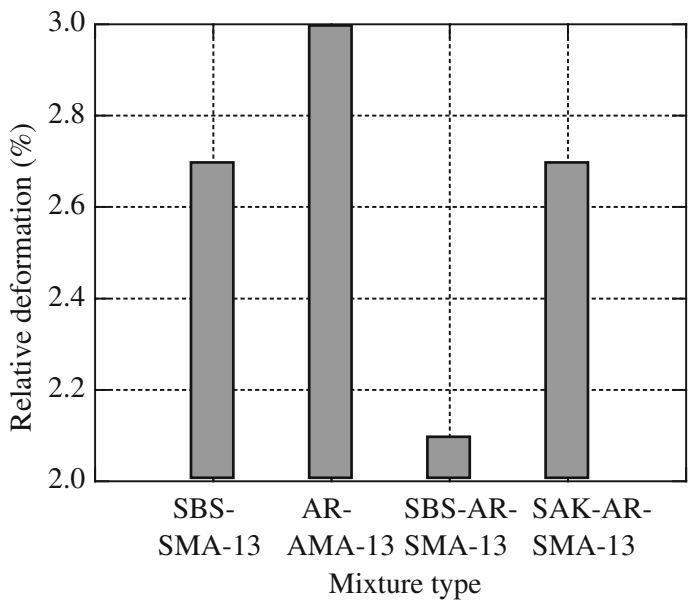

(b) Relative deformations

Fig. 3 Comparison of rutting test results

(2) Compared with AR-SMA-13, the DS of SBS-ARSMA-13 increased by $66.3 \%$ and the relative deformation increased by $30.0 \%$. The DS of SAKAR-SMA-13 increased by $15.5 \%$ and its relative deformation increased by $10.0 \%$. Therefore, compound modification can improve high-temperature stability.

(3) The high-temperature viscosity of SBS asphalt was lower than that of pure asphalt-rubber, but SBSSMA-13 had good rutting resistance. Therefore, for different types of asphalt with different mechanisms, the viscosity index is unilateral at times. We now need to integrate factors comprehensively to evaluate the high-temperature performance of asphalt and its mixtures.

\subsection{Effect of molding parameters}

During the rutting test, the molding temperature and rolling times were closely related to the compactness and stability of the mixture. As demonstrated in the current standard
(JTG E20-2011), 12 round-trips are recommended for the rolling time for molding rutting test specimens. The compactness of the baseline asphalt mixture meets the specification demand after 12 round-trips of wheel-rolling. The standard also recommends a temperature of approximately $140-170{ }^{\circ} \mathrm{C}$ to mold rutting test specimens. Because of the properties of high viscosity asphalt-rubber, the compactness and high-temperature stability of the asphalt-rubber mixture with recommended molding parameters are far below standard values [19].

We selected rolling time and forming temperature as molding parameters to analyze the compaction effect on high-temperature performance of the asphalt-rubber mixture.

\subsubsection{Rolling times for compaction}

Different rolling times $(10,12,14,16,18,20,22$, and 24 round-trips) were selected for molding asphalt-rubber mixture specimens at uniform temperature $\left(180{ }^{\circ} \mathrm{C}\right)$. From Fig. 4, we conclude that:

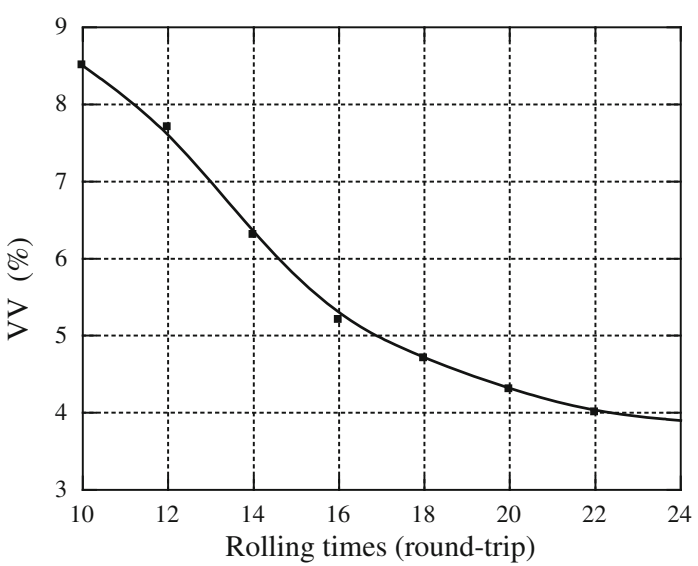

(a) Volume of air voids

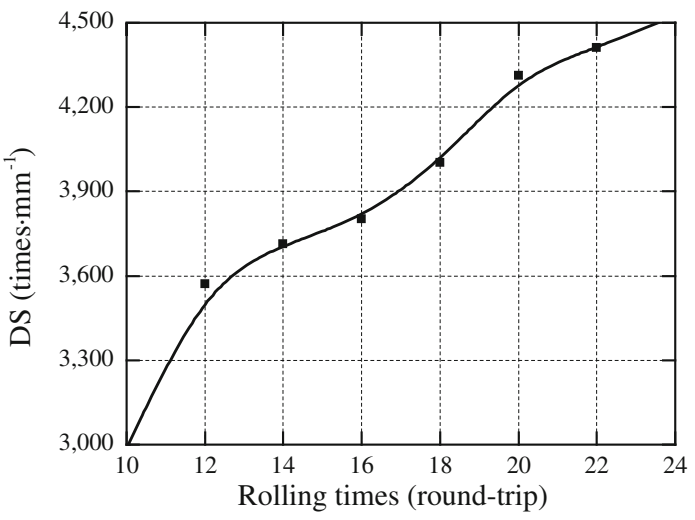

(b) Dynamic stability

Fig. 4 Relationship between VV and DS with rolling time 


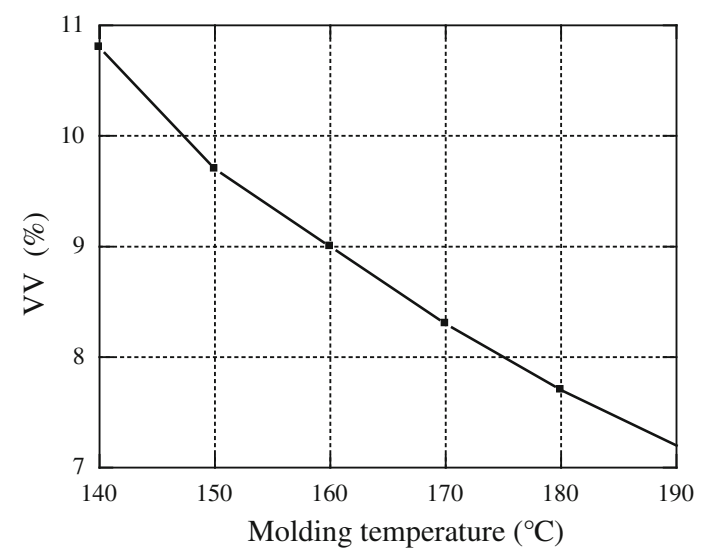

(a)

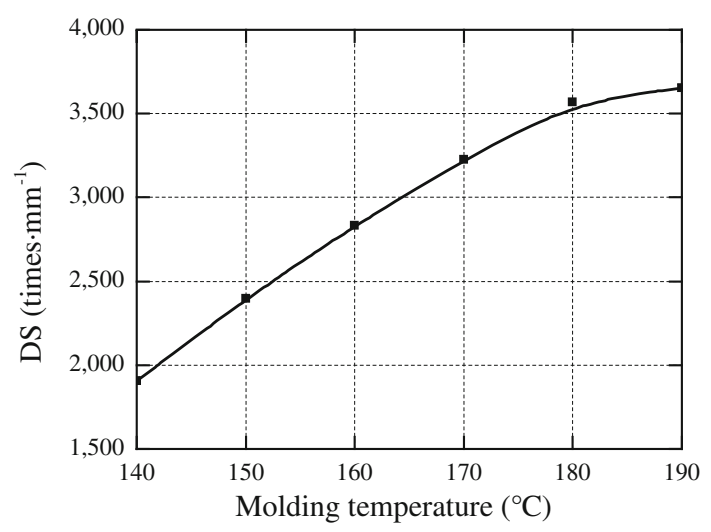

(b)

Fig. 5 Relationship of VV and DS with molding temperature

(1) The VV decreases with increase in rolling time, but the rate of change decreases gradually. If the asphaltrubber mixture is compacted with 12 round-trips by the wheel-rolling method, its VV is $7.7 \%$ (larger than the objective of $3 \%-5 \%$ [11]). This occurs because the viscosity of the asphalt-rubber binder is high, there is a thick covering of the aggregate with asphalt mortar, and the asphalt-rubber mixture is therefore harder to compact.

(2) The compactness of the asphalt-rubber mixture increases with increase in rolling time and therefore the DS increases significantly. For the asphalt-rubber mixture, an increase in rolling time contributes to better structural strength and stability. To enhance mixture compactness and achieve high-temperature stability, the rolling times of the asphalt-rubber mixture should be controlled strictly. However, if the compactness were too high, it would result in interference between the binder and aggregate and bleeding in the asphalt pavement. So that the mixture VV reaches its objective value (3\%-5\% [11]) and so that there is no interference in compaction, the rolling times for molding asphalt-rubber mixtures should be controlled between 18 and 20 round-trips.

\subsubsection{Molding temperature}

Different molding temperatures $(140,150,160,170,180$, and $190{ }^{\circ} \mathrm{C}$ ) were chosen to mold rutting specimens at uniform rolling times (12 round-trips). As shown in Fig. 5, the molding temperature was closely related to the VV and DS. The VV decreased with increase in molding temperature. As the molding temperature increased, the hightemperature stability of the asphalt-rubber mixture improved significantly. The VV of the mixture molded at $140{ }^{\circ} \mathrm{C}$ was 1.5 times that molded at $190{ }^{\circ} \mathrm{C}$ and the DS was $52.1 \%$ of those molded at $190{ }^{\circ} \mathrm{C}$. Figure $5 \mathrm{~b}$ indicates that with decline in temperature, the downtrend of the DS was more significant. The compaction temperature must therefore be controlled strictly to ensure good performance of the asphalt-rubber mixture. If the rolling time to mold rutting specimens is set at 12 round-trips, the temperature must be controlled at $180-190{ }^{\circ} \mathrm{C}$ to meet technical standards (DS $\geq 3,500$ times $\mathrm{mm}^{-1}$ ).

\section{Conclusion}

(1) The high-temperature stability of the mixtures varied as: AR-SMA-13 > AR-AC-13 > AC-13. The hightemperature performance of AR-SMA-13 can be improved by adjustment of the SMA-13 gradation. This results in a decrease of the $0.075-\mathrm{mm}$ passing percentage from 10 to $8 \%$ and that of the $2.36-\mathrm{mm}$ passing percentage from 20.5 to $18.5 \%$.

(2) The effects of compound modification in asphaltrubber are significant. The comprehensive high-temperature performance of $\mathrm{S}-\mathrm{R}$ asphalt is better than the other types of asphalt. Compared with pure asphaltrubber, the K-R asphalt with SAK improved the hightemperature performance indices, such as, the softening point, penetration, and elastic recovery. Its viscosity reduced significantly and therefore enhances mixture compactness to yield structural strength.

(3) The high-temperature performance of the four mixtures was: SBS-AR-SMA-13 > SAK-AR-SMA$13 \approx$ SBS-SMA-13 > AR-SMA-13. The high-temperature stability can therefore be improved by compound modification, especially SBS compound modification in asphalt-rubber.

(4) Compaction parameters, such as, molding temperature and rolling times were closely related to the hightemperature stability of the asphalt-rubber mixture. With increase in rolling time, the compactness and 
dynamic stability of the asphalt-rubber mixtures increased gradually and the rolling times for molding the asphalt-rubber mixtures should be controlled for $18-20$ round-trips at uniform temperature $\left(180{ }^{\circ} \mathrm{C}\right)$. With decrease in compaction temperature, the compactness and dynamic stability of the asphalt-rubber mixture decreased by degrees. If setting rolling times of 12 round-trips were used as the uniform case (as for the SBS asphalt mixture), the compaction temperature must be controlled at $180-190{ }^{\circ} \mathrm{C}$ to meet technical standards.

Open Access This article is distributed under the terms of the Creative Commons Attribution License which permits any use, distribution, and reproduction in any medium, provided the original author(s) and the source are credited.

\section{References}

1. Yang ZF, Li MJ, Wang XD (2005) The history and status of rubber powder used in road-building. J Mater Civ Eng 22(7):19-22 (in Chinese)

2. Bahia HU, Davies R (1994) Effect of crumb rubber modifier (CRM) on performance related properties of asphalt binders. J Assoc Asphalt Paving Technol 63:414-438

3. Sun ZW, Chen B (2007) Guide for technical application of asphalt rubber. China Communications Press, Beijing (in Chinese)

4. Anderson J, Pampulim V, Saim R, et al (2000) Asphalt rubber laboratory properties related to type and process technology of crumb rubber. In: Asphalt Rubber 2000 Proceedings, Portugal, pp 371-382

5. Huang P, Lv WM, Zhang FQ et al (2001) Research on performance and technology of the rubber powder modified asphalt mixture. China J Highw Transp 14(12):2-5 (in Chinese)

6. Shen J, Amirkhanian S (2005) The influence of crumb rubber modifier (CRM) microstructures on the high temperature properties of CRM binders. Int J Pavement Eng 6(4):265-271
7. Bennert T, Hanson D, Maher A et al (2005) Influence of pavement surface type on tire/pavement generated noise. J Test Eval 33(2):94-100

8. Wang XD, Li MJ, Lu KJ et al (2008) The applied technology of the crumb rubber in the asphalt and mixture. China Communications Press, Beijing, pp 111-124 (in Chinese)

9. Ye ZG, Kong XM, Yu JY et al (2003) Investigation on crumb rubber modified asphalt. J Wuhan Univ Technol 25(1):11-14 (in Chinese)

10. Ling TQ, Xiao C, Xia W et al (2010) Characteristics of asphaltrubber mortar and aggregate gradation optimization based on high temperature condition. J Civ Archit Environ Eng 32(5):47-52 (in Chinese)

11. Ministry of Communications Highway Research Institute (2008) Guide for design and construction of asphalt rubber and mixtures. China Communications Press, Beijing (in Chinese)

12. Arizona Department of Transportation Standard Specifications for Road \& Bridge Construction, Phoenix, AZ, 2000

13. Pasquini E, Canestrari F, Cardone F et al (2011) Performance evaluation of gap graded asphalt rubber mixtures. Constr Build Mater 25(4):2014-2022

14. P.R. China Ministry of Communications (2011) Standard test methods of bitumen and bituminous mixtures for highway engineering (JTG E20-2011). China Communications Press, Beijing (in Chinese)

15. P.R. China Ministry of Communications (2004) Technical specifications for construction of highway asphalt pavement (JTG F40-2004). China Communications Press, Beijing (in Chinese)

16. Lu XH, Isacsson U, Ekblad J (1999) Phase separation of SBS polymer modified bitumens. J Mater Civ Eng 11(1):51-57

17. Wang T, Cai HM, Zhang YZ (2008) Study on mechanism of SBS modified asphalt. Pet Asphalt 6(22):10-14 (in Chinese)

18. Gao XF, Liu LP, Liu HF et al (2009) Performance evaluation of warm-asphalt mixture with SAK. Highw Eng 34(6):51-54 (in Chinese)

19. Xiao C (2009) Research on high temperature performance and construction technology of asphalt-rubber and mixture. Dissertation, Congqing Jiaotong University, Chongqing (in Chinese)

20. Huang WD, Wei W, Huang $Y$ et al (2010) Influencing factor research on high-temperature performance of asphalt rubber mixture. J Tongji Univ 38(7):1023-1028 (in Chinese) 